\title{
Knowledge, attitudes and practices regarding echinococcosis in Xizang Autonomous Region, China
}

Nima Qucuo ${ }^{1 \dagger}$, Guangjian Wu $\mathrm{W}^{2,34}$, Ruifeng $\mathrm{He}^{1}$, Danzeng Quzhen ${ }^{1}$, Ciren Zhuoga', Suolang Deji', Lijie Zhang ${ }^{5^{*}}$, Zhigang Zhao ${ }^{3^{*}}$ and Zhongjun Du ${ }^{6^{*}}$ (D)

\begin{abstract}
Background: Echinococcosis is a neglected zoonotic parasitic disease caused echinococcus parasitizes, poseing a significant economic burden on both humans and animals. There are limited studies on echinococcosis in China, especially Xizang Autonomous Region, although the area is endemic area for echinococcosis. The study aimed to provide information for strategic prevention against this disease.
\end{abstract}

Methods: A cross-sectional survey was conducted among the residents in Xizang Autonomous Region, China to evaluate their knowledge, attitudes and practices on endemicity of echinococcosis. A face-to-face survey was conducted to collect the data using a well-designed questionnaire. The contents included basic personal information, knowledge, attitudes and practices about echinococcosis, personal hygiene and behavior habits, dog feeding and whether they had received the information on echinococcosis, and so on. We surveyed 840 persons in practice. All data analysis was performed using Epi Info 7.2.

Results: Of the total particpants, $86.8 \%$ had a primary education level or below (including primary and illiterate), and even $45.0 \%$ were illiterate. Farmers and herdsmen represent the main occupations in this study. People who know all the echinococcosis-related knowledge in the questionnaire only accounted for $8.7 \%$ of the participants. However, none of the participants was aware of routes of echinococcosis infection in human or dogs. The data showed participants with higher educational background had the high awareness rate of echinococcosis-related knowledge or attitudes (chi-square for trend, $x^{2}=21.23, p<0.05 \& x^{2}=48.43, p<0.05$ ). In addition, The percentage of the participant with awareness of echinococcosis-related practices was associated with their age and principle occupation ( $\left.x^{2}=52.72, p<0.05 \& x^{2}=20.63, p<0.05\right)$.

Conclusions: Xizang Autonomous Region is an epidemic area of Echinococcosis. The prevalence of the disease has been largely due to the lack of knowledge, awareness, and poor hygiene practice in local residences. Therefore, effective disease prevention education and awareness campaigns in community will be significantly helpful in prevention and control of echinococcosis.

Keywords: Echinococcosis, Prevention, Xizang Autonomous Region, China

\footnotetext{
*Correspondence: cfetpzlj@126.com; zhgzh1982@163.com;

duzj1981@163.com

${ }^{\dagger}$ Nima Qucuo and Guangjian Wu contributed equally to this work and

should be considered co-first authors

${ }^{5}$ Chinese Center For Disease Control And Prevention, Beijing 100050, Beijing,

People's Republic of China

${ }^{3}$ Shandong Center for Disease Control and Prevention, Jinan 250014,

Shandong Province, People's Republic of China

${ }^{6}$ Shandong Academy of Occupational Health and Occupational Medicine,

Shandong Academy of Medical Sciences, No. 18877, Jingshi Road, Jinan,

Shandong Province 250062, People's Republic of China

Full list of author information is available at the end of the article
}

(c) The Author(s). 2020 Open Access This article is distributed under the terms of the Creative Commons Attribution 4.0 International License (http://creativecommons.org/licenses/by/4.0/), which permits unrestricted use, distribution, and reproduction in any medium, provided you give appropriate credit to the original author(s) and the source, provide a link to the Creative Commons license, and indicate if changes were made. The Creative Commons Public Domain Dedication waiver (http://creativecommons.org/publicdomain/zero/1.0/) applies to the data made available in this article, unless otherwise stated. 


\section{Background}

Echinococcosis is a zoonotic parasitic disease caused by echinococcus parasitizes infection in humans (or animals). It seriously endangers people's health and life safety, and affects social and economic development [1]. Cysticercosis echinococcosis (CE) and Alveolar echinococcosis (AE) are caused by E.granulosus and E.Multilocularis infections, respectively [2]. CE is prevalent in most pastoral and range land areas of the world. Highly endemic areas are mainly located in the eastern Mediterranean, Western China, Southern and Eastern Europe, North Africa, the southern part of America, Siberia and Central Asia [3]. AE is prevalent in high latitudes of the Northern Hemisphere countries, such as North America, continental Europe, Siberia, Central Asia, Japan and China [3]. Among them, Gansu, western Sichuan and the Tibetan Plateau in China are the most serious areas of alveolar echinococcosis in the world [4].

In China, AE is also known as "worm cancer", a fatal and serious disease [5] which is difficult to treat with poor prognosis [6]. After $\mathrm{AE}$ infection, the fatality rate of untreated can be large than $90 \%$, even as high as $94 \%$ $[6,7]$. Echinococcosis not only affects human health and causes human lives to be lost due to significant morbidity and mortality, but also brings about economic loss related to livestock husbandry $[8,9]$. The economic loss relating to livestock husbandry can further worsen the accessibility of medical intervention causing a tremendous impact on the health of patients, even with loss of their lives [1]. It is estimated that China accounts for $40 \%$ of the world's 1 million disability-adjusted life years (DALYs) caused by CE, and accounts for $34 \%$ of the world's annual losses of US\$ 1.92 billion due to CE. China also held an important share in the annual global livestock production losses associated with $\mathrm{CE}$, reaching US\$ 2.92 billion [8]. Previous studies have shown that $\mathrm{CE}$ can reduce the productivity of infected animals by $10 \%$, lowering meat quality, milk and fiber production and the number of surviving offspring [10]. The annual number of new cases of AE in China accounts for 91\% of the global total of new AE cases, and responsible for 95\% of the global DALYs and the corresponding years of life lost (YLLs) due to AE [11].

$\mathrm{CE}$ is a chronic, complex disease and defined as a neglected tropical disease (NTD) by the World Health Organization (WHO) [12]. Four options for the treatment of CE are currently available: (1) surgery, (2) chemotherapy with albendazole, mebendazole or other anthelmintic drugs, (3) PAIR (puncture, aspiration, injection, reaspiration), (4) watch and wait for inactive or silent cysts [13]. At present, there is no optimum treatment for $\mathrm{CE}$, and there are no clinical trials to compare the different modalities [14]. Because of the constraints in the health-care system [15], there is no standard for choosing treatment options of CE leaving surgery being still the main method of treatment [16]. Although surgery, as the classic treatment is curative way, it cannot completely prevent recurrence of the disease [14]. In addition, surgery is not suitable for patients with multiple cysts in several organs [2, 14, 17]. With the development and progress of medical technologies, CE can be diagnosed primarily utilizing imaging, immunology, molecular biology and puncture biopsy [13]. In the meantime, a large number of insecticides have been put into use, which has achieved certain results in reducing the incidence of CE [13]. Longterm use of chemical drugs leaves other problems such as drug resistance, drug residues, environmental pollution, and so on [13].

Previous studies have shown that the transmission of echinococcosis is influenced by the economic and cultural conditions of the community [8, 9]. The most important factors are associated with dog, such as 'close contact with dogs', 'home-raising dogs', 'feeding dogs with the viscera of diseased animals', followed by dietary factors, such as 'lack of washing hands before meals', "drinking river or stream water" [18-20].

To effectively prevent and control echinococcosis, it is very important to evaluate the level of knowledge about the disease, increase awareness regarding the preventive measures and awareness of risky practices that spread the disease within the community. The objective of this study was to obtain information on the current situation of knowledge, attitudes and practices about echinococcosis among the residents of Xizang Autonomous Region. In addition the aim was also to determine current health promotion activities, to provide helpful information for the improvement and formulation of health education policies for the future.

\section{Methods}

This study was a cross-sectional survey conducted in Xizang Autonomous Region, which locates in the west and south of the Qinghai-Tibet Plateau. It accounts for more than half of the area of the Qinghai-Tibet Plateau. Lhasa is the capital city of Xizang Autonomous Region. The most area of the region is above $4000 \mathrm{~m}$ above sea level. As such, Xizang is known as the 'the roof of the World' and "the third pole of the earth", and the highest elevation in the world (Fig. 1).

\section{Study subjects}

The study subjects were permanent residents of Xizang Autonomous Region (Residence time $\geq 6$ months). 


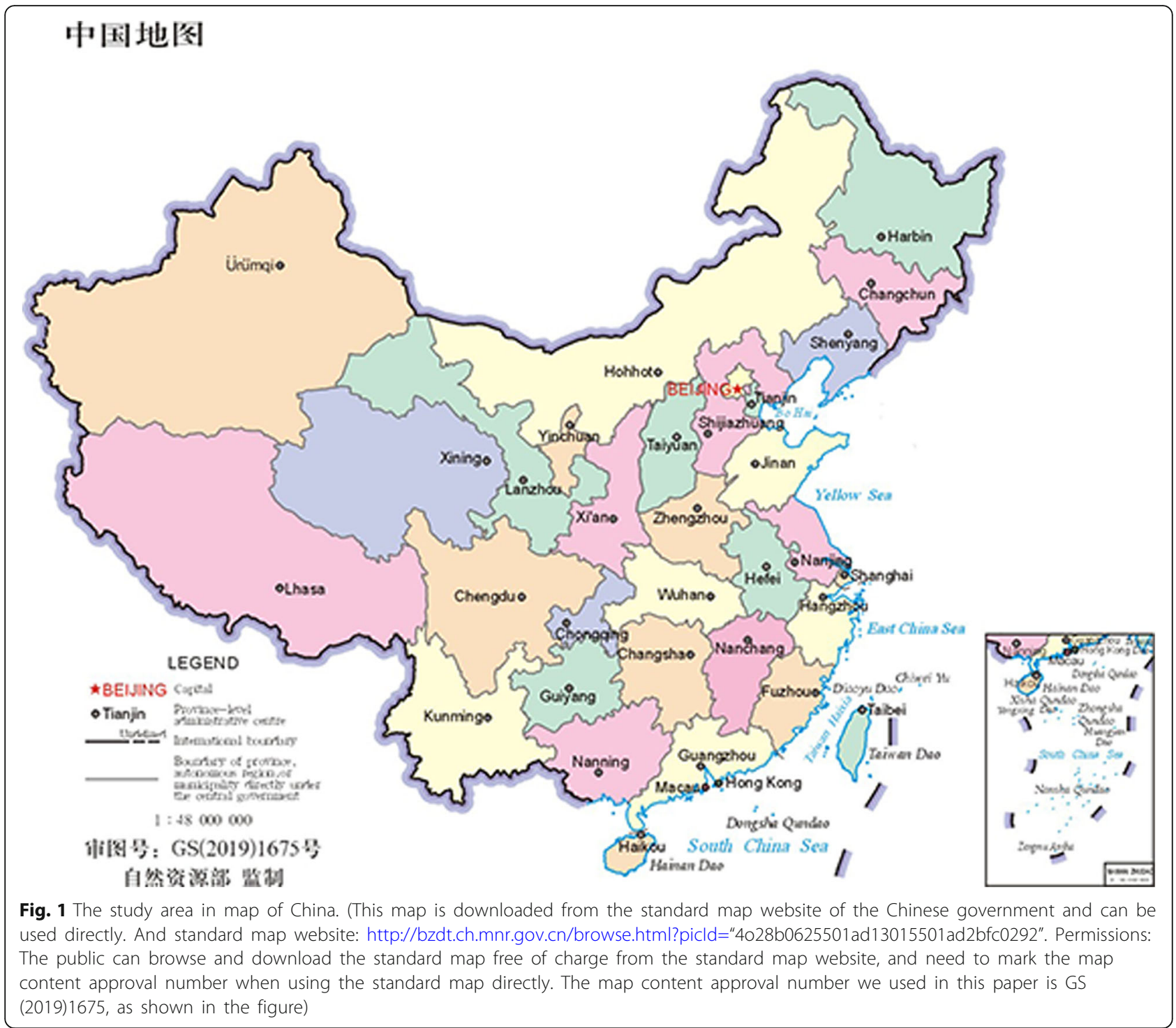

\section{Sample size calculation}

Calculating sample size was based on simple random sampling.

formula:

$$
n=\frac{u_{a / 2}^{2} \pi(1-\pi)}{\delta^{2}}
$$

Test significance level was set $\alpha=0.05$, admissible error $\delta=10 \%$, cognitive eligibility rate was $33 \%$ according to the literature. In this study, a multi-stage complex sampling method was used. The design effectiveness was set at 1.5 and the sample size was set at 600 since with a $10 \%$ non-response rate, the minimum sample size should be 667 .

\section{Sampling method}

Sampling stratification was conducted according to numbers of prefectures and municipalities in Xizang Autonomous Region, and the seven prefectures were divided into seven layers. In each prefecture, three counties (districts) were randomly selected by a simple random sampling method. In each selected counties (districts) two townships and two villages were further randomly selected according to the simple random sampling method. In each selected village selected, 10 local villagers were randomly selected according to the simple random sampling method. Totally, 840 subjects were selected for this study.

\section{Questionnaire design}

The questionnaire (Additional file 1) was developed in Chinese by the Xizang Autonomous Region Center for 
Disease Control and Prevention based on their past experience and a literature review of comparable studies [21-23]. A series of question were listed with point for each question, and zero for ignorance or mistake. The total scores of knowledge, attitudes and practices of echinococcosis are 15, 6 and 6 respectively. Referring to the "health literacy level of infectious disease prevention and control among Chinese residents" [24], we defined criteria for overall assessment. A total score of $80 \%$ or more in each part is classified as high awareness. Therefore, a participant is said to have "high level of awareness" if-- the total score of echinococcosis-knowledge is at least 12 points; if the total score of echinococcosisattitudes is at least 6 points and total score of echinococcosis-practices is at least 6 points.

\section{Data analysis}

We used Epidata 3.5.1 to double input the data. Participants' socio-demographic characteristics such as age, gender, education level and principle occupation were presented as frequencies and percentages. The awareness rate of knowledge, attitudes and practices of echinococcosis were calculated as follow:

Rate of echinococcosis knowledge = the number of people who answered a certain knowledge correctly divided by the total number of people being investigated $\times 100 \%$. Attitude holding rate $=$ the number of people who held a certain attitude divided by the total number of people being investigated $\times 100 \%$. Practice formation rate $=$ the number of people who formed a certain practice divided by the total number of people being investigated $\times 100 \%$.

The chi-square test was used to analyse the differences between social demographic characteristics and the awareness rates of relevant indicators. Additionally, the chi-square test for trend was applied to investigate the ordering of awareness rates among the indicators. All data analyses were performed using Epi Info 7.2 (https://www.cdc.gov/epiinfo/pc.html) at 5\% level of significant.

\section{Results}

\section{Socio-demographic characteristics of the study population}

The information of socio-demographic characteristics was summarized in in Table 1, Age of the interviewed sujects ranged from 12 to 79 years (mean: $40.9 \pm 14.0$ standard deviation). The ratio of male to female was 1.3:1. The great majority (86.8\%) of the interviewed residents had a primary education level or below, and as many as 45.0\% were illiterate. Farmers and herdsmen were the main occupations in this study.
Table 1 Socio-demographic characteristics of the residents participated in echinococcosis knowledge, attitudes and practices survey in Xizang Autonomous Region, China $(N=840)$

\begin{tabular}{llll}
\hline Variables & Category & $\mathrm{n}$ & $\%$ \\
\hline Age (years) & $\leq 20$ & 38 & 4.5 \\
& $21 \sim 30$ & 184 & 21.9 \\
& $31 \sim 40$ & 256 & 30.5 \\
& $41 \sim 50$ & 145 & 17.3 \\
& $51 \sim 60$ & 123 & 14.6 \\
& $61 \sim 70$ & 76 & 9.0 \\
Gender & $>70$ & 18 & 2.1 \\
& Male & 478 & 56.9 \\
& Female & 362 & 43.1 \\
& Illiterate & 378 & 45.0 \\
& Primary & 351 & 41.8 \\
& Secondary & 59 & 7.0 \\
& University & 52 & 6.2 \\
& Farmers & 415 & 49.4 \\
& Herdsmen & 274 & 32.6 \\
& Other & 50 & 6.0 \\
& Cadres or professional technicians & 43 & 5.1 \\
& Workers & 30 & 3.6 \\
& Students & 28 & 3.3 \\
\hline
\end{tabular}

A lack of echinococcosis-related knowledge among the subjects

Awareness rate of echinococcosis-related knowledge

Only 73 persons answered all 15 questions about echinococcosis correctly, accounting for $8.7 \%$ (73/840) of the participants. The awareness rates of non-transmission of echinococcosis about human-to-human, human-to-dog and dog-to-dog were all very low. Only $1 / 4$ of the respondents knew that echinococcosis cannot be transmitted by dog-to-dog, were showed in Table 2 .

\section{The high awareness rate of echinococcosis-related knowledge}

The high awareness rate of echinococcosis-related knowledge of the residents in Xizang Autonomous Region was $66.1 \%(555 / 840)$. The qualified awareness rate of echinococcosis-related knowledge was not related to gender, age or occupation. With the improvement of the education level, the qualified awareness rate shows an upward trend (chi square for trend, $\chi^{2}=21.23$, $p<0.05)$, as shown in Table 3.

\section{Investigation of echinococcosis-related attitudes}

The high awareness rate of echinococcosis-related attitudes of the residents in Xizang Autonomous Region was $48.9 \%$ (411/840). The high awareness rate for males was higher than for females $\left(x^{2}=5.70, p<0.05\right)$. The high 
Table 2 Awareness rate of echinococcosis-related knowledge among residents of Xizang Autonomous Region, China, 2018 ( $N=840)$

\begin{tabular}{|c|c|c|c|}
\hline Theme & Variables & Number of awareness & Rate (\%) \\
\hline \multirow[t]{5}{*}{ Routes of human infection } & Have you ever heard of echinococcosis? & 826 & 98.3 \\
\hline & $\begin{array}{l}\text { Contaminated food by dog manure containing insect eggs } \\
\text { can cause disease in humans or livestock }\end{array}$ & 759 & 90.4 \\
\hline & $\begin{array}{l}\text { Contaminated water by dog manure containing insect eggs can } \\
\text { cause disease in humans or livestock }\end{array}$ & 745 & 88.7 \\
\hline & Cannot be transmitted by human-to-human & 391 & 46.5 \\
\hline & Besides dogs, wolves and foxes can also transmit echinococcosis & 586 & 69.8 \\
\hline \multirow[t]{3}{*}{ Routes of dogs infection } & Can be transmitted by dog-to-dog & 213 & 25.4 \\
\hline & Cannot be transmitted by human-to-dog & 422 & 50.2 \\
\hline & Dogs are infected by eating the uncooked viscera of sick cattle and sheep & 704 & 83.8 \\
\hline \multirow[t]{2}{*}{ Damage } & Damage to human health & 793 & 94.4 \\
\hline & Cause reduction of cattle and sheep production & 704 & 83.8 \\
\hline \multirow[t]{5}{*}{ Prevention } & Expelling parasite for dogs & 651 & 77.5 \\
\hline & Cannot feed dogs with uncooked viscera of livestock & 722 & 86.0 \\
\hline & Handle dog manure (be burned or deeply buried) & 693 & 82.5 \\
\hline & Don't be in close contact with dogs in life (such as kissing or touching) & 690 & 82.1 \\
\hline & Wash hands frequently and before meals to develop good personal hygiene habits & 771 & 91.8 \\
\hline
\end{tabular}

Table 3 The qualified awareness rate of echinococcosis-related knowledge among residents of Xizang Autonomous Region, China, $2018(N=840)$

\begin{tabular}{|c|c|c|c|c|c|c|}
\hline Theme & Variables & Number of people surveyed & Number of qualified persons & $\begin{array}{l}\text { The qualified } \\
\text { awareness rate }\end{array}$ & $x^{2}$ & $p$ \\
\hline \multirow[t]{2}{*}{ Gender } & Male & 478 & 251 & 52.5 & 2.71 & 0.10 \\
\hline & Female & 362 & 160 & 44.2 & & \\
\hline \multirow[t]{7}{*}{ Age (years) } & $\leq 20$ & 38 & 7 & 18.4 & 7.84 & 0.25 \\
\hline & $21 \sim 30$ & 184 & 73 & 39.7 & & \\
\hline & $31 \sim 40$ & 256 & 160 & 62.5 & & \\
\hline & $41 \sim 50$ & 145 & 77 & 53.1 & & \\
\hline & $51 \sim 60$ & 123 & 56 & 45.5 & & \\
\hline & $61 \sim 70$ & 76 & 32 & 42.1 & & \\
\hline & $>70$ & 18 & 6 & 33.3 & & \\
\hline \multirow[t]{4}{*}{ Education level } & Illiterate & 378 & 162 & 42.9 & $21.23^{\mathrm{a}}$ & 0.00 \\
\hline & Primary & 351 & 172 & 49.0 & & \\
\hline & Secondary & 59 & 38 & 64.4 & & \\
\hline & University & 52 & 39 & 75.0 & & \\
\hline \multirow[t]{6}{*}{ Principle occupation } & Farmers & 415 & 202 & 48.7 & 10.82 & 0.06 \\
\hline & Herdsmen & 274 & 140 & 51.1 & & \\
\hline & Other & 50 & 20 & 40.0 & & \\
\hline & Cadres or professional technicians & 43 & 26 & 60.5 & & \\
\hline & Workers & 30 & 17 & 56.7 & & \\
\hline & Students & 28 & 6 & 21.4 & & \\
\hline
\end{tabular}


awareness rate of echinococcosis-related attitudes among different age groups had a significant difference $\left(\chi^{2}=\right.$ $48.43, p<0.05)$, and the 30-40 age group had the highest high awareness rate. With the improvement in the educational level, the high awareness rate shows an upward trend (chi-square for trend $x^{2}=48.43, p<0.05$ ). The high awareness rate of echinococcosis-related attitudes was not related to principle occupation $\left(x^{2}=10.82, p>0.05\right)$, as shown in Table 4.

\section{Investigation of echinococcosis-related practices}

The high awareness rate of echinococcosis-related practices of the residents in Xizang Autonomous Region was $47.9 \%(402 / 840)$. The development of echinococcosisrelated practices was not related to gender and education level, instead they were related to age and principal occupation, as shown in Table 5.

\section{Discussion}

Xizang is an autonomous region with a low socioeconomic status. It is sparsely populated with approximately 3.3 million inhabitants. Most inhabitants live in rural areas with poor sanitary facilities. A large proportion of inhabitants is affiliated with animal husbandry and agriculture. They come into close contact with animals and their living habits and daily practice are not strictly adhered to, hygiene principles, thus exposing them to a high risk of acquiring echinococcosis infection.

It is established that the transmission of echinococcosis is primarily related to educational level, human behavior, lifestyle, living habit and, environmental factors [24]. Health education can play a vital role in reducing transmission of echinococcosis to humans [25]. To prevent and control echinococcosis, it is necessary to draw awareness to improper behaviors, such as lifestyle and living habits that increase susceptibility to echinococcosis in the general population and guide the residents to establish good attitudes towards echinococcosis prevention and control, to change their bad behaviors. In underdeveloped or resource poor communities where education is inadequate and there are high levels of illiteracy, echinococcosis is often highly endemic [26].

This study revealed that the majority $(86.8 \%)$ of the interviewed residents had a primary level of education or below that. During our investigation in the villages, feces shed by dogs were visible on the ground in most villages, providing evidence that a considerable proportion of dogs are allowed to roam free. This potentially endangers children who like to play and crawl on the ground, thereby increasing the oral-fecal route of transmission of echinoccocus [25].

A major challenge is to introduce educational materials on echinococcosis into targeted populations with

Table 4 The high awareness rate of echinococcosis-related attitudes among residents of Xizang Autonomous Region, China, 2018

$(N=840)$

\begin{tabular}{|c|c|c|c|c|c|c|}
\hline Theme & Variables & $\begin{array}{l}\text { Number of people } \\
\text { surveyed }\end{array}$ & $\begin{array}{l}\text { Number of } \\
\text { qualified persons }\end{array}$ & $\begin{array}{l}\text { The qualified } \\
\text { awareness rate }\end{array}$ & $x^{2}$ & $p$ \\
\hline \multirow[t]{2}{*}{ Gender } & Male & 478 & 327 & 68.4 & 5.70 & 0.02 \\
\hline & Female & 362 & 228 & 63.0 & & \\
\hline \multirow[t]{7}{*}{ Age (years) } & $\leq 20$ & 38 & 22 & 57.9 & 48.43 & 0.00 \\
\hline & $21 \sim 30$ & 184 & 125 & 67.9 & & \\
\hline & $31 \sim 40$ & 256 & 173 & 67.6 & & \\
\hline & $41 \sim 50$ & 145 & 97 & 66.9 & & \\
\hline & $51 \sim 60$ & 123 & 82 & 66.7 & & \\
\hline & $61 \sim 70$ & 76 & 46 & 60.5 & & \\
\hline & $>70$ & 18 & 10 & 55.6 & & \\
\hline \multirow[t]{4}{*}{ Education level } & Illiterate & 378 & 232 & 61.4 & $23.34^{\mathrm{a}}$ & 0.00 \\
\hline & Primary & 351 & 243 & 69.2 & & \\
\hline & Secondary & 59 & 42 & 71.2 & & \\
\hline & University & 52 & 38 & 73.1 & & \\
\hline \multirow[t]{6}{*}{ Principle occupation } & Farmers & 415 & 288 & 69.4 & 7.15 & 0.21 \\
\hline & Herdsmen & 274 & 167 & 60.9 & & \\
\hline & Other & 50 & 32 & 64.0 & & \\
\hline & Cadres or professional technicians & 43 & 32 & 74.4 & & \\
\hline & Workers & 30 & 19 & 63.3 & & \\
\hline & Students & 28 & 17 & 60.7 & & \\
\hline
\end{tabular}


Table 5 The high awareness rate of echinococcosis-related practices among residents of Xizang Autonomous Region, China, 2018 $(N=840)$

\begin{tabular}{|c|c|c|c|c|c|c|}
\hline Theme & Variables & $\begin{array}{l}\text { Number of people } \\
\text { surveyed }\end{array}$ & $\begin{array}{l}\text { Number of } \\
\text { qualified persons }\end{array}$ & $\begin{array}{l}\text { The qualified } \\
\text { awareness rate }\end{array}$ & $x^{2}$ & $p$ \\
\hline \multirow[t]{2}{*}{ Gender } & Male & 478 & 223 & 46.7 & 0.65 & 0.42 \\
\hline & Female & 362 & 179 & 49.4 & & \\
\hline \multirow[t]{7}{*}{ Age (years) } & $\leq 20$ & 38 & 11 & 28.9 & 52.72 & 0.00 \\
\hline & $21 \sim 30$ & 184 & 62 & 33.7 & & \\
\hline & $31 \sim 40$ & 256 & 113 & 44.1 & & \\
\hline & $41 \sim 50$ & 145 & 90 & 62.1 & & \\
\hline & $51 \sim 60$ & 123 & 74 & 60.2 & & \\
\hline & $61 \sim 70$ & 76 & 48 & 63.2 & & \\
\hline & $>70$ & 18 & 4 & 22.2 & & \\
\hline \multirow[t]{4}{*}{ Education level } & Illiterate & 378 & 179 & 47.4 & 1.48 & 0.69 \\
\hline & Primary & 351 & 165 & 47.0 & & \\
\hline & Secondary & 59 & 29 & 49.2 & & \\
\hline & University & 52 & 29 & 55.8 & & \\
\hline \multirow[t]{6}{*}{ Principle occupation } & Farmers & 415 & 197 & 47.5 & 20.63 & 0.00 \\
\hline & Herdsmen & 274 & 124 & 45.3 & & \\
\hline & Other & 50 & 23 & 46.0 & & \\
\hline & Cadres or professional technicians & 43 & 30 & 69.8 & & \\
\hline & Workers & 30 & 17 & 56.7 & & \\
\hline & Students & 28 & 10 & 35.7 & & \\
\hline
\end{tabular}

low levels of literacy, and increase awareness of selfprotection among the residents. Previous study has shown that due to a high proportion of illiteracy with few children going to school, education of dog owners and their children about echinococcosis control was only partly achieved on the Tibetan plateau [27]. Our study also confirmed that the education level of the participants affected their attitudes and practices towards echinococcosis. Data from our study showed the risk of echinococcosis was reduced with the increase in education level. Our study also revealed that only a small proportion of the interviewed residents are familiar with all the echinococcosis-related knowledge. A large proportion was not aware of the routes of echinococcosis infection in human or dogs. The lack of awareness of the echinococcosis infection routes led to ignorance the disease prevention. On the other hand, this strongly suggested that health education on echinococcosis in Xizang is not sufficient which worsen the epidemic of the disease.

Change in practice needs is much dependent on knowledge and attitudes. At present, both the high awareness rate of echinococcosis-related knowledge and attitudes of residents in Xizang Autonomous Region were low. Therefore, improving their echinococcosis-related knowledge and changing their attitudes might be the breakthrough points at this stage. Educational materials should be produced and distributed to the population. Considering the high level of illiteracy in the subjects, The education materials should be easy to understand and taught to the targeted population [24]. To highlight the intervention effect positively and create A strong social ethos that can encourage people to prevent and control echinococcosis is critically important for an effective intervention.

Our study only studied the relationship between demographic characteristics and knowledge, attitudes and practices. External factors related to the transmission of echinococcosis, such as environmental factors and family factors, need to be further explored.

\section{Conclusions}

The epidemic of the disease has been largely resutantant from the lack of knowledge, awareness, and poor hygiene practice in local residences. Therefore, effective disease prevention education and awareness campaigns in community will be significantly helpful in prevention and control of echinococcosis. Improving the level of knowledge of echinococcosis is the basis for residents to prevent and control echinococcosis while changing attitudes is a key factor, and developing good practices represent effective means of achieving that goal. 


\section{Supplementary information}

Supplementary information accompanies this paper at https://doi.org/10. 1186/s12889-020-8314-8.

Additional file 1. Questionnaire.

\section{Abbreviations}

AE: Alveolar echinococcosis; CDC: Center for Disease Control and Prevention; CE: Cysticercosis echinococcosis; DALYs: Disability-adjusted life years; WHO: World Health Organization; YLLs: Years of life lost

\section{Acknowledgements}

Not applicable.

\section{Authors' contributions}

Conceived and designed the experiments: LZ, ZZ and ZD. Performed the experiments: NQ, GW, RH, DQ, CZ and SD. Analysed the data and performed the statistical analysis: NQ and GW. Helped analysed the data and provided critical strategic advice $\mathrm{RH}, \mathrm{DQ}$, and $\mathrm{CZ}$. Wrote the paper: NQ and GW. The paper was revised by LZ, ZZ and ZD. And ZD provided research fund. All authors read and approved the final version of the manuscript.

\section{Funding}

This work was supported by the National Natural Science Foundation of China [grant number 81602893], Natural Science Foundation of Shandong Province [grant number ZR2015YL049], Medical and Health Technology Development Plan Project of Shandong Province [grant number 2016WS0540], and Key Research and Development Plan of Shandong Province [grant number 2018GSF118018]. The funding agencies did not affect the design of research, the collection, analysis and interpretation of data, or the writing of papers.

\section{Availability of data and materials}

All data and materials for this study shall be availed whenever requested by the editorial team, reviewers and other users. The data and materials can be requested from the corresponding author.

\section{Ethics approval and consent to participate}

Ethics and approvals were sought and granted from Xizang Autonomous Region Center for Disease Control and Prevention (Approval for ethical review of biomedical research involving humans, 2017-025), and obtained the written informed consent of all the participants. Participation of subjects was voluntary and written consent was obtained from all participants before data collection.

\section{Consent for publication}

Not applicable.

\section{Competing interests}

The authors declare that they have no competing interests.

\section{Author details}

${ }^{1}$ Xizang Autonomous Region Center for Disease Control and Prevention, Lasa 850000, Xizang Autonomous Region, People's Republic of China. ${ }^{2}$ School of Public Health, Jilin University, Changchun 130021, Jilin Province, People's Republic of China. ${ }^{3}$ Shandong Center for Disease Control and Prevention, Jinan 250014, Shandong Province, People's Republic of China. ${ }^{4}$ Academy of Preventive Medicine, Shandong University, Jinan 250014, Shandong Province, People's Republic of China. ${ }^{5}$ Chinese Center For Disease Control And Prevention, Beijing 100050, Beijing, People's Republic of China. 'Shandong Academy of Occupational Health and Occupational Medicine, Shandong Academy of Medical Sciences, No. 18877, Jingshi Road, Jinan, Shandong Province 250062, People's Republic of China.
Received: 21 July 2019 Accepted: 3 February 2020

Published online: 15 April 2020

\section{References}

1. Qian MB, Abela-Ridder B, Wu WP, Zhou XN. Combating echinococcosis in China: strengthening the research and development. Infect Dis Poverty. 2017;6(1):161.

2. Mcmanus DP, Zhang W, Li J, Bartley PB. Echinococcosis. Lancet. 2003; 362(9392):1295-304.

3. Moro P, Schantz PM. Echinococcosis: a review. Int J Infect Dis. 2009;13: 125-33.

4. Han J, Bao G, Zhang D, Gao P, Wu T, Craig P, Giraudoux P, Chen X, Xin Q, He $L$, Chen $G$, Jing T. A newly discovered epidemic area of Echinococcus multilocularis in West Gansu Province in China. PLoS One. 2015;10(7): e0132731.

5. Ji X-w, Zhang J-h, Zhao J-m, et al. Liver transplantation for the treatment of end-stage hepatic alveolar echinococcosis. Chin J Digest Surg. 2011;10(4): 299-301.

6. Huang F, Dang Z, Sutaka Y, Horiuchi T, Yagi K, Kouguchi H, Irie T, Kim K, Oku $Y$. Analysis on gene expression profile in Oncospheres and early stage Metacestodes from Echinococcus multilocularis. PLoS Negl Trop Dis. 2016; 10(4):e0004634

7. Jura H, Bader A, Hartmann M, et al. Hepatic tissue culture model for study of host-parasite interactions in alveolar echinococcosis. Infect Immun. 1996; 64(9):3484-90

8. Budke CM, Deplazes P, Torgerson PR. Global socioeconomic impact of cystic echinococcosis. Emerg Infect Dis. 2006;12(2):296-303.

9. Singh BB, Dhand NK, Ghatak S, Gill JP. Economic losses due to cystic echinococcosis in India: need for urgent action to control the disease. Prev Vet Med. 2014;113(1):1-12

10. Battelli G. Echinococcosis: costs, losses and social consequences of a neglected zoonosis. Vet Res Commun. 2009:33(1 Supplement):47-52.

11. Torgerson PR, Keller K, Magnotta M, Raqland N. The global burden of alveolar Echinococcosis. PLoS Negl Trop Dis. 2010;4(6):e722.

12. Merino V, Westgard CM, Bayer AM, Garcia PJ. Knowledge, attitudes, and practices regarding cystic echinococcosis and sheep herding in Peru: a mixed-methods approach. BMC Vet Res. 2017;13(1):213.

13. Velascotirado V, Alonsosardón M, Lopezbernus A, Romero-Alegría A, Burguillo FJ, Muro A, Carpio-Pérez A, Muñoz Bellido JL, Pardo-Lledias J, Cordero M, Belhassen-García M. Medical treatment of cystic echinococcosis: systematic review and meta-analysis. BMC Infect Dis. 2018;18(1):306.

14. Brunetti E, Kern P, Vuitton DA. Expert consensus for the diagnosis and treatment of cystic and alveolar echinococcosis in humans. Acta Trop. 2010; 114(1):0-16.

15. Vuitton DA. Benzimidazoles for the treatment of cystic and alveolar echinococcosis: what is the consensus? Expert Rev Anti-Infect Ther. 2009; 7(2):145-9.

16. Junghanss $T$, da Silva AM, Horton J, Chiodini PL, Brunetti E. Clinical management of cystic echinococcosis: state of the art, problems, and perspectives. Am J Trop Med Hyg. 2008;79(3):301-11.

17. Tekin $\mathrm{R}$, Onat $\mathrm{S}$, Tekin RC. Hydatid cysts in a patient with multiple organ involvement. Rev Soc Bras Med Trop. 2016:49(4):534

18. Romig T, Omer RA, Zeyhle E, Hüttner M, Dinkel A, Siefert L, Elmahdi IE, Magambo J, Ocaido M, Menezes CN, Ahmed ME, Mbae C, Grobusch MP, Kern P. Echinococcosis in sub-Saharan Africa: emerging complexity. Vet Parasitol. 2011:181(1):43-7.

19. Hu HH, Wu WP, Guan YY, Wang LY, Wang Q, Cai HX, Huang Y. A villagebased multidisciplinary study on factors affecting the intensity of cystic echinococcosis in an endemic region of the Tibetan plateau, China. Epidemiol Infect. 2014;142(6):1214-20.

20. Ibrahim MM. Study of cystic echinococcosis in slaughtered animals in A Baha region, Saudi Arabia: interaction between some biotic and abiotic factors. Acta Trop. 2010;113(1):0-33.

21. Han Z, Yin Y, Zhang Y, Ehrhardt S, Thio CL, Nelson KE, et al. Knowledge of and attitudes towards hepatitis $B$ and its transmission from mother to child among pregnant women in Guangdong Province, China. PloS one. 2017; 12(6):e0178671.

22. Chan OK, Lao T, Suen SS, Lau TK, Leung TY. Knowledge on hepatitis B infection among pregnant women in a high endemicity area. Patient Educ Counsel. 2010;85:516-20. 
23. Jha S, Devaliya D, Bergson S, Desai S. Hepatitis B knowledge among women of childbearing age in three slums in Mumbai: a cross-sectional survey. Hepatol Med Policy. 2016;1 (1):5.

24. Shi-Long Q, Ze-Qing DI, Min F, et al. Health literacy and influencing factors of infectious disease prevention among migrating individuals engaging in construction and hotel services in Hubei. Chin Prevent Med. 2016;17(9):65154. https://doi.org/10.16506/j.1009-6639.2016.09.003.

25. Craig PS, Hegglin D, Lightowlers MW, Torgerson PR, Wang Q. Echinococcosis: control and prevention. Adv Parasitol. 2017;96:55-158.

26. Ito A, Urbani CQ, Vuitton DA, Dongchuan Q, Heath DD, Craig PS, Zheng F, Schantz PM. Control of echinococcosis and cysticercosis: a public health challenge to international cooperation in China. Acta Trop. 2003;86:3-17.

27. Heath D, Yang W, Li T, Xiao Y, Chen X, Huang Y, Yang Y, Wang Q, Qiu J. Control of hydatidosis. Parasitol Int. 2006;55(Suppl):S247-52.

\section{Publisher's Note}

Springer Nature remains neutral with regard to jurisdictional claims in published maps and institutional affiliations.

Ready to submit your research? Choose BMC and benefit from:

- fast, convenient online submission

- thorough peer review by experienced researchers in your field

- rapid publication on acceptance

- support for research data, including large and complex data types

- gold Open Access which fosters wider collaboration and increased citations

- maximum visibility for your research: over $100 \mathrm{M}$ website views per year

At $\mathrm{BMC}$, research is always in progress.

Learn more biomedcentral.com/submissions 